\title{
Preparing the Child for Productive Life
}

\section{Stella Baindu Fortune}

\section{Senior Lecturer}

\section{Eastern Polytechnic Education Department}

\author{
Kenema, Sierra Leone \\ baindufortune@gmail.com
}

\begin{abstract}
The nature of children's development is greatly influenced by the environmental conditions in which they are brought up. The amount of social stimulation which they receive is of particular importance, and even if physical conditions are adequate, an unstimulating environment which provides with little opportunity or need to experiment or solve problems will result in low level of achievement. Perhaps the most important aspect of the child's social development is beyond the reach of the teacher. For the first very important aspect of the child's development lies in the home. Genetic endowment and cultural level of the family, coupled with the actual physical conditions of the home will have decisive effect on the child's development and will continue to influence him throughout his school life. These factors are inaccessible to be influenced by the teacher but it is as well for him to have them in mind in his dealings with pupils. In addition, he will need to know how he may most effectively change his pupils along the lives he considers to be the most appropriate. That is, he will seek out the most efficient ways of getting pupils learn for productive life in future.The topic under review will be approached from various fronts which include; The Sociological and Philosophical models; role of the school; Learners' responsibility; role of
\end{abstract}


the teacher; discipline and learner control; role of the parent; guidance and counseling services and conclusion.

\section{Introduction}

It could be accepted that the school itself is an organic, dynamic entity capable of equipping learners for a constructive place in society. The goals of education in Sierra Leone are clear enough as the National Policy on Education emphasizes. Pupils in schools and students in colleges and universities endeavor to pursue education to help them succeed in their work and obtain good jobs. All young people think about their future work and lives and expect the schools not merely to prepare them for life in future but to do reasonably well in preparing the child to be acceptable in society and also for examinations, and for the next higher educational level. But today, there is increasing concern about the need for schools to prepare our children for productive life in future.

\section{Sociological and Philosophical Models}

Sociology is generally defined as the science that studies people either as individuals or as groups of people in communities, institutions or organizations that together make up the human society; and the studies would include all aspects of human social life. Sociology is also understood as positive humanizing science since it is concerned with studies of how people relate to one another and to their environment; it also includes community or group formations, forms of, and reasons for, the different types of human attitudes and behavior, as well as the designs and roles of the social structures that reflect the net-workings of the interrelationships that shape the lives of the members of the society as they endeavor to cope with the problems of crime, inequalities, poverty and other social problems. In a paper published by Dr, Ron J. Hammond and Dr. Paul Cheney on smash words, it was quoted that 
"Sociology is defined as a Science of Society" The above definitions imply that, sociological studies are of great academic importance that suitably responds to the other sciences to express their true functions in the web of human intellectual achievements. Therefore, sociology examines and records as active facts, both the structural aspects of human society as well as all forms of social relationships that exist within such structures. Accordingly, anyone involved in and concerned about the positive serving of society - from the school teacher to the college professor, from the researcher to the inventor and innovator, from policy makers and planners to administrators and implementers, from the small rural farmer to the industrial and business conglomerates, from the social worker to the extension agent, and everyone who honorably serves human society, is by right a sociologist; this is because, in their respective professional ways, they are all objectively confronting the realities of society and of human relationships such that they could make factual judgments and take responsibility for such judgments with the view of finding honest solutions to the numerous problems of society.

Sociology is as old as the time people sought ways of effecting realistic social cohesion and finding lasting solutions to social conflicts. But as a science, sociology could be dated to the time people began to advance social-scientific reasoning to solve social problems; but concepts of sociology existed in most cultures before they were adopted with the advent of western civilization. The greatest form of conflict which people have carried on with nature in their attempt to maintain the independence and individuality of their existence is mankind's inherent antagonism towards any form of power - whether political, religious or cultural - that tends to inhibit the freedom to be an independent individual capable of achieving the person's potentials that enhance one's individual uniqueness and indispensability; however, this does not make anyone absolutely independent of the complementary action of the other members of society. 
Sociology thus seeks to deal with this primitive conflict by applying scientific reasoning to positively affirm human conduct without limiting the freedom and individuality of the person as he/she finds acknowledgement as a dutiful servant of human society to make some input in maintaining sustainable rural livelihoods. Nevertheless, Philosophy endeavors to search for an understanding of the mysteries of reality and existence with the view of discovering the nature of truth and knowledge and thereby find the intrinsic value and importance in life. So that, while sociology studies the relational aspects of people living in human institutions and societies, philosophy seeks to examine the relationships between humanity and nature in order to bring out the functionalities of individuals in societies; and whereas sociology issues mostly from the human desire to establish his/her freedom to be unique and indispensable, philosophy largely issues out of human amazement and curiosity with a strong desire to know and give clarified understanding of issues and situations through speculations, analysis, criticisms and interpretations.

And Education is the process of acquiring knowledge, skills, habits and attitudes to help people appreciate their cultural traditions and the world around them. This enables people to become useful citizens of society such that they could live more accomplished lives. The knowledge, skills, habits, values and attitudes that one acquires as a child help to shape one's character from childhood and influence the beliefs and thoughts of people throughout life. And as people continue to grow in societies that have established distinctive values and beliefs, sociology and philosophy will remain as important issues in their education. This is true because everything that is taught by the educational systems of societies reflect the sociological and philosophical ideals that affect the existence of that particular society as the people aspire to cope with the challenges of a dynamic and changing world as is constantly influenced by the cultural, traditional and behavioral patterns of the society. 
For whereas, sociological issues are mostly concerned with the "affective" or character, education that deals with the development of feelings, values and appreciation, philosophical matters mainly deal with the "cognitive" or perceptive education that aims at increasing one's knowledge and intellectual skills. Accordingly, sociological issues in education help people to develop relevant moral and spiritual values - including healthy attitudes and emotions, to assist people relate usefully to others in their societies; but philosophical issues, on the other hand, help people to develop the ability to think and reason effectively, especially as philosophy tends to satisfy curiosity through answering questions to solve problems with the view of discovering the truth. So that just as sociology addresses aspects of human social life, so is philosophy the love of wisdom that endeavors to discover the nature of truth and knowledge.

Consequently, education must commence at an early age, most appropriately at the Pre-school age, when the mind of the child is ready to receive through a strong inclination to improving on the powers of observation, imitation and imagination, especially when very strongly attached to the parents. At that age, the child's mind is described as a "clean sheet" on which anything could be written. So the parents who are the most important initial teachers must aim at teaching children the right attitudes and values that would help to shape the character of children for a long time in their lives. And as children outgrow the Pre-school age and gradually become active explorers of the world around them, particularly when they begin to distinguish between right and wrong, they become increasingly aware of the people around them and then unconsciously learn the behavioral standards of their communities and societies through identification, observation and imitation. And as the child approaches the early school age, the professional educators then take over from the parents to handle the increasing development of the child's mental, emotional, social and psychological potentials. It is at this age that children increasingly become independent as they develop skills of 
problem solving and gain more confidence in their mental abilities. Bogdan R. and Biklin S. (1998) in their abstract (Quality Research for Education) quoted thus 'A According to the social-historical theory, interaction between individuals plays a major role in building the human being. It is through such interpersonal relationships that the individual's psychological development takes place'’.

Consequently, children would begin to form self-images of themselves as such images are influenced by the people with whom they interact; therefore, a child's self-image could be either positive or negative depending on the attitudinal and emotional values impressed upon their minds by the people with whom they identify. Subsequently, it is important for all stakeholders in the child's early development, including the parents, professionals, educationists and other care-givers to be good role-models for children under their tutelage. This is especially important as the children enter the pre-adolescent age when their peergroup relationships increasingly and more powerfully influence their character modeling considering that they look more to their peer-groups for acceptance and approval. It should never be overlooked that pre-adolescent children judge themselves by the standards of their peer-group associations such that self-images of growing children change noticeably under the pressure of their peer-group members.

\section{Role of the School}

Writers from various social science disciplines continue to refer to schools as cultural communities. Communities that have their own mission statements with their own governance structures, rules and regulations. To fully understand the cultural characteristics of a school, one has to delve deeply into the embedded institutional practices. By and large, success and failure of school depends largely on who the leader is. This statement is not only true of schools but all societal institutions. The administrator has a number of very various 
duties, inclusive of his concern with the quality of instruction as well as the pupil's welfare; and also his concern with the moral and spiritual tone of the school and maintenance of good discipline.

All major researches on innovation and school effectiveness show that the head of the school influences the likelihood of change, but it also indicates that most institutional heads do play instrumental leadership roles. If the school were to adequately prepare the child for productive life, then the administrator must continue to be dedicated and committed to the work towards the vision and mission of the institution.

\section{Learner's Responsibility}

Learners must take active role in their learning by realizing that they are accountable for their own academic success. Learners therefore need to demonstrate the charisma of making choices and taking actions which would lead them towards their educational goals. Responsible learners take ownership of their actions by exhibiting the following behaviors. They demonstrate academic integrity and honesty.

Attend and participate in classes and all school works.

Complete the assigned work in a timely manner with attention to quality of work.

Avoid making excuses for their behavior.

Communicate in a careful and respectful manner with teachers, peers, and other members of the community.

Act in a civil manner that respects the school learning/social environment and complies with school policies as outlined by the administrationUtilize school resources and seek help when needed. Respect diverse ideas and opinions.

Identify, develop, and implement a plan to achieve their educational goals.

Each student's ability to learn and gain the best possible rewards from his/her college 
experience depends upon an environment which is conducive to learning and to activities which are consistent with the objectives of an academic institution. Subsequently, the school should be a place which encourages dialogue and even differences, and teaches children how to live in a world where everyone is not alike and everyone does not agree. Therefore, the most productive thing children can do is listen - truly listen - to each other and treat each other with respect. Children are expected to demonstrate love and use good judgment in their words and actions. Working together, they can create a positive atmosphere in which all can learn and grow.

Providing an atmosphere that promotes honesty and the free exchange of ideas is the essence of academic obligation to uphold high intellectual and ethical standards. Academic integrity includes adherence to codes of ethical behavior associated with the school and the community.

Role of the Teacher

Equally important is the role that teachers play in the life of the institutions; the role of the teacher is crucial in the life of the school, because the success and failure of school depend upon the quality and strength of the staff. Whether or not pupils are successful learners depend largely upon the quality of the personal interaction between the pupils and their teachers. As put by Beattie M., quoting Berscheid (1985, p. 60), 'In the context of professional learning and in the processes of responding to others and developing the abilities to be more response able, prospective teachers move beyond the limitations of their own knowing; learning to learn from and with others and engage in the co-construction of meanings'. Agreeing with Beattie M., the researcher strongly believes that professional relationship between the teachers, put the teacher in better position to give guidance and specialized help to the child. 
Note: Change that involves re-socialization and interaction between and among teachers is the primary basics for social learning. New methodologies, new meanings, new behavior and new innovations depend significantly on whether teachers are working as isolated individuals or exchanging ideas and extending support and positive feeling towards their work. Teachers therefore are urged to engage in more positive ways of thinking and doing. Thus the teacher has to be role model to his learners.

\section{Discipline and Learner Control}

As quoted by Oyieyo Dickson Mokaye in his research paper- Influence of Guidance and Counselling on student Discipline in Public Secondary Schools In Kabondo Division, Kenya, (2012),

" Discipline is a rudimentary ingredient that plays a crucial role in school system and insists on upholding the moral values of students. It is intended to suppress, control and redirect behaviour. In a school system all students must be aware of the rules before disciplinary action can be administered' .

In respect of the above view, discipline is another important thing to ensure in schools.. No one questions that the administrator is responsible for his school, but there is some doubt as to who is responsible for the learners in it. Parents, guidance, teachers and the general public as well as the administrator all get involved. Few people would deny that parents have the major responsibility for discipline and that the schools and other community agencies merely complement their effort. But if parents fail to address their responsibilities, how far should the administrator and teachers replace them?

Children are expected to behave according to the norms and values of society. But the rapidly changing condition of life today often demands that individuals should be able to think and act in new ways and to form responsible judgment for themselves. 
By and large, the administrator and staff should set good example of self-control and self-discipline in the classes and throughout the school. Faith in the desire and ability of students to do the right things and socially accepted things do much to create trust and selfconfidence. The positive approach to discipline does not mean that students are given license to do as they please, but to obtain positive theory of effective discipline.

In this regard, the administration must ensure strict discipline in the school if our boys and girls are to be prepared for productive lives.

Role of the Parent

Every man is born to a family group and most of our actions are patterned after the groups to which we belong. In light of that, sociologists designed three different home atmospheres that may affect the child' personality in various ways.

\section{Democratic}

If a child is coming from a democratic home, he is expected to be curious, explanatory and he also expresses his feelings and ideas freely. That child needs guidance so that he does not go beyond bounds.

\section{Autocratic}

On the contrary the autocratic home atmosphere discourages children from acting independently. Such children will be timid, awkward, and apprehensive. They will not express their ideas and feelings freely. Ensure that such children participation in school activities like debates, games and sports and demonstration lessons.

\section{Leissez faire}

The third home atmosphere sociologist wrote about is the leissez faire home which 
encourages nonchalant behavior, lawlessness and such children will never take life seriously. They can be recalcitrant. They need guidance and counseling

Children need guidance and counseling for development of self-control. They must learn to control their basic feelings which include affections, anxiety and anger.

Affection: Let them learn to ask when they need or want something.

Anxiety: Children should not get themselves unnecessarily worried that could lead to nervousness or attack of panic.

Anger: Guide them to realize that they should not blow things out of proportion when they are angry. They should learn to control their emotions when they are antagonized. Parents must teach children to internalize the norms and values of their culture.

Education is a process which involves the cooperation of teachers, parents, learners and the community. In light of the above statement, the functioning of the school can never be meaningful without the cooperation of the parents in particular and the community in general. It is with a popular view that the provision of social status is one of the paramount functions performed by the family and that children inherit a special social position because of the family background and reputation of the parents'.

Chaquenta L. Smith quotes. 'Several studies examine the impact the family structure has on a child's quality of life. Each of those found that family structure had some level of effect on the child's educational attainment and health outcomes', Agreeing with Chaquenta L. Smith, the researcher is with the opinion that, family resources affect children's ability to pursue certain opportunities such as higher education and specialized lessons" therefore, it is strongly believed that it is the responsibility of the parents to assume ultimate protection and upbringing of children; as children need constant care and economic security. So that parents carefully examine the culture of the home and the culture of the society as these two cultures affect the child's educational expectations. Considering how attitude could 
affect children's educational attainment, it will also be of paramount importance if parents strictly monitor the peer-group relationships of children; since this relationship of children's adolescent stage increasingly and unbearably influences their education as they look to their peer groups than to parents for acceptance and approval.

However, it is popularly believed that the home is a very important institution for developing the child's moral, spiritual and socialization patterns as the child develops his or her basic gender roles including the possession of basic fundamental skills considered as good standard behavior for the community in which the child grows up.

Charles II Cooley called the family, a primary group in the socialization process because Primary Groups are characterized by intimate face-to-face association and cooperation. According to him the family is the most important socializing institution because:

- It is small

- Parents have strong ties to the child. The parents show love, empathy, trust, warmth and interdependence to the child

- The child spends most of his time with the family

- Also the patterns of social interaction within the family may provide unintended models for the later behavior and personality traits of the children.

He further stated that the family has three (3) Major Goals in Socializing the Child including:

i. $\quad$ The development of self-control: The child learns to express and control these basic feelings: affection, anxiety and anger.

ii. $\quad$ The internalization of society's values, norms and mores. The family as a primary agent of socialization is responsible for the molding of the child's personality to the point where these control values of the society's culture become a part of him or her. 
iii. $\quad$ The acceptance of role behavior. The child learns the art of role behavior by observing and imitating the behavior of their parents.

Guidance and Counseling Services

Literally, guidance means "to direct", "to point out", "to show the path". But guidance is not exactly the process of directing. While in directing, one imposes his opinion on others rather guidance means providing some help or assistance to somebody by somebody. If we accept this meaning, guidance will be as old as mankind. Because man at each and every stage or sphere of life needs guidance from others.

If this will be the meaning of guidance then this treatment will come under the purview of a very broader and general meaning of guidance which will also convey the modern meaning of guidance.

But in narrower view and perspective, guidance is interpreted as a specialized service to help the individual to solve certain major problems - personal, educational, vocational and the like.

This is so because, for some it is a concept, a point of view; for others, it is a process, a group of services; and for some, it is a field of study. So guidance is accepted as both a concept and a process and must be interpreted accordingly in the educational process. As a concept, guidance is concerned with the maximum development of the individual to make his own decisions. As a process, it makes the individual aware of his abilities and potentialities. The purpose is to make him confident in selecting appropriate course of action for adjustment in various works of life and helping the individual for balanced development. Guidance involves personal help given by someone; In consonant of the above, Oyieyo Dickson Mokaye in his research paper- Influence of Guidance and Counselling on student Discipline in Public Secondary Schools In Kabondo Division, Kenya, quoted thus. 
'Globally, guidance and counselling services are essential elements in discipline management of people in all societies. School guidance and counselling programmes have therefore been introduced to assist students overcome the number of challenges they experience at home and at school'.

\section{Counseling}

Counseling is designed to assist the individual to decide where he wants to go, what he wants to do, and how best he can accomplish his purpose; give expert advice support in terms of trouble or giving encouragement. It is a learning-oriented process, which occurs in an interactive relationship between the counselor and the counselee with the aim of helping the children to learn more about the self and to use such understanding to become an effective member of the society. Therefore, it is important for children to be given Guidance and Counseling services to help them acquire the capacity and capability for self-direction. The researcher strongly believes that it is through guidance and counseling that the learner is aided to grow in the ability to solve his own problems and thereby achieve the ultimate aim of education. It is therefore important that learners are given adequate guidance and counseling services in order to adopt certain behaviors leading to specific goals and careers.

Subsequently, such guidance as vocational, educational, personal and social guidance are needed, so that the experiences given to children become total and not partial.

\section{Conclusion}

We are social beings and so in some ways or other, we need help and guidance of others- parents, grandparents, teachers and other elders for successful living. Due to explosion of knowledge, industrialization and changes in socio-economic set up the need for professional guidance is felt in the present day society. 
To be knowledgeable about the society, they are growing up so as to increase their growing up total awareness sense of self confidence in order to tackle new situations with interest and lack of fear.

Children must learn to obey the Laws of the Sierra Leonean Society, beginning from the home, they should practice their cultural beliefs for example.

Guide female students to build a positive attitude towards science subjects including mathematics.

Also the agents of socialization serving as guidance counselor must provide learners with the skills, awareness and knowledge which will enable them to confront social inadequacies. That is, lack of competence. Guide and counsel them enough for them to be confident of themselves so as to confront issues of their day-to-day lives 


\section{References}

Beattie, M. (2000). Educational leadership: Modeling, mentoring, making and remaking a learning community: Paper presented at the annual meeting of the American Educational Research Association, New Orleans.

Bogdan, R. \& Biklin, S. (1998). Qualitative Research for Education: An introduction to theory and methods (2nd edition), Needham Heights, MA: Allyn \& Bacon. Chibber, S.K. (1999).

Chaquenta L. Smith .University of Kentucky - Effects Of Family Structure On Educational Attainment And Health Insurance Coverage Of Youth In The Lower Mississippi Delta Region

Dr, Ron J. Hammond and Dr. Paul Cheney (smash words) - A publication paper- Introduction to Sociology by Dr, Ron J. Hammond.

Oyieyo Dickson Mokaye. A research paper- Influence of Guidance and Counselling on student Discipline in Public Secondary Schools In Kabondo Division, Kenya, (2012). 